\title{
Fast Disassembly of Lignocellulosic Biomass to Lignin and Sugars by Molten Salt Hydrate at Low Temperature for Overall Biorefinery
}

\author{
Zhihao Bi, Bin Lai, Yi Zhao, and Lifeng Yan*(-) \\ Department of Chemical Physics, iCHEM, University of Science and Technology of China, Hefei 230026, P. R. China \\ Supporting Information
}

ABSTRACT: Lignocellulose is a complex of cellulose, hemicellulose, and lignin, whose overall conversion is still a challenge, especially by a fast and efficient method. Here, a very simple method has been developed using acidic molten salt of zinc chloride hydrate as the solvent and catalyst for complete disassembly of lignocellulose at $95{ }^{\circ} \mathrm{C}$ and atmospheric pressure in $12 \mathrm{~min}$. The major products are lignin and monosaccharides, such as glucose and xylose. It was found that high-purity lignin in yield of about $20 \mathrm{wt} \%$ can be obtained with various biomass, and the maximum yield of glucose from bamboo is $40.56 \mathrm{wt} \%$ and that of xylose from wheat straw is 16.82 wt \%. Importantly, zinc chloride can be recovered through precipitation by ammonia and reused for next cycles. It provides a simple route to separate and efficiently convert lignocellulose, especially high-grade feedstock for biorefinery.

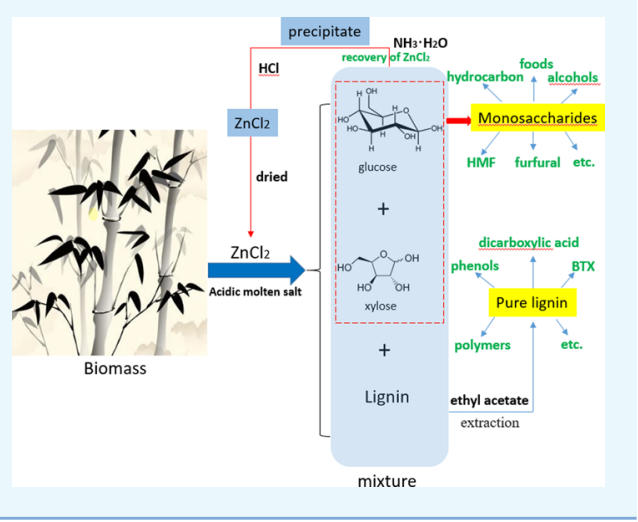

\section{INTRODUCTION}

Lignocellulosic biomass, a kind of renewable carbon resource, has attracted much attention to produce biomass-based fuels and other platform chemicals or materials. ${ }^{1}$ Lignin, cellulose, and hemicellulose are the three major component biopolymers of lignocellulosic biomass and potential feedstock that can serve as alternative to fossil resources in the near future. It is still a challenge to find a new and efficient method to convert lignocellulose and its components into valuable chemicals or materials. Nowadays, two routes have been employed for this conversion: (i) depolymerization of lignocellulose directly without distinguishing its components, such as thermal pyrolysis and gasification, which usually regard biomass as a mixture of $\mathrm{C}, \mathrm{H}$, and $\mathrm{O}$ elements, and the degraded products are so complex that upgrade is generally required, ${ }^{2}$ and (ii) fractionation of lignocellulose to cellulose, hemicellulose, or lignin and then their conversion to the desired chemicals or materials, with the major obstacle being efficient disassembly of the robust complex. ${ }^{3}$ A similar problem was also faced by paper-making industries, especially for the nonwoody biomass.

From a chemical perspective, the interactions among the three major components include hydrogen bonding between the cellulose and lignin, as well as between the cellulose and hemicellulose, and covalent bonds (mainly ether bonds) between cellulose and lignin. Therefore, disassembly of lignocellulose usually requires rigorous chemical or special physical treatment, with plenty of pollutants formed during the processes. Recently, green solvents and technologies have been developed to solve this problem, and ionic liquids are known for their ability to directly dissolve cellulose, hemicellulose, lignin, and even raw lignocellulose at low temperature, and have been used as solvents for biomass green conversion. ${ }^{4}$ However, ionic liquids are still expensive, and their recovery and reuse is still a challenge. As a kind of ionic liquid-like system, inorganic molten salt hydrates are inexpensive and easily obtained. In addition, they are environmentally friendly due to their nontoxicity and nonvolatility. Interestingly, it is well known that molten salt hydrates have excellent ability to dissolve polysaccharides, such as cellulose and hemicellulose, and can be used as media for their hydrolysis, ${ }^{5}$ such as cellulose hydrolysis in acidified $\mathrm{LiBr}$ molten salt hydrate media ${ }^{6}$ and synthesis of furfurals from biopolymers in molten salt hydrate. ${ }^{7}$ However, they showed limited ability to dissolve lignin, which provides an opportunity to quantitate lignin in lignocellulosic biomass, such as acidic lithium bromide trihydrate. ${ }^{8}$ The key point of efficient utilization of lignocelluloses is their disassembly by a simple and mild method and then conversion of the relative fractions to valuable building block molecules, intermediates, or materials. So, molten salt hydrates may be a suitable medium for efficient and direct production of lignin and relative monosaccharides in a one-pot process, especially with various molten salt hydrates by recovery and reutilization.

Lignin is a complex aromatic polymer with network structure that consists of three phenylpropane units, $p$-hydroxyphenyl $(\mathrm{H})$, guaiacyl $(\mathrm{G})$, and syringyl $(\mathrm{S})$, linked through $\beta-\mathrm{O}-4$ and $\mathrm{C}-\mathrm{C}$ bonds in different combinations. ${ }^{9}$ The ratio of phenylpropane units and the amount of linkages and functional groups are significantly different, depending on plant species. ${ }^{10}$ Many researchers have conducted a great deal of experiments to study the isolation and quantitation of lignin from lignocellulose to enhance the utilization of lignin for chemicals and biofuels in the biorefinery. ${ }^{11}$ However, the formation of

Received: January 10, 2018

Accepted: February 28, 2018

Published: March 12, 2018 
Scheme 1. Schematic of the Method for Lignin Quantitation
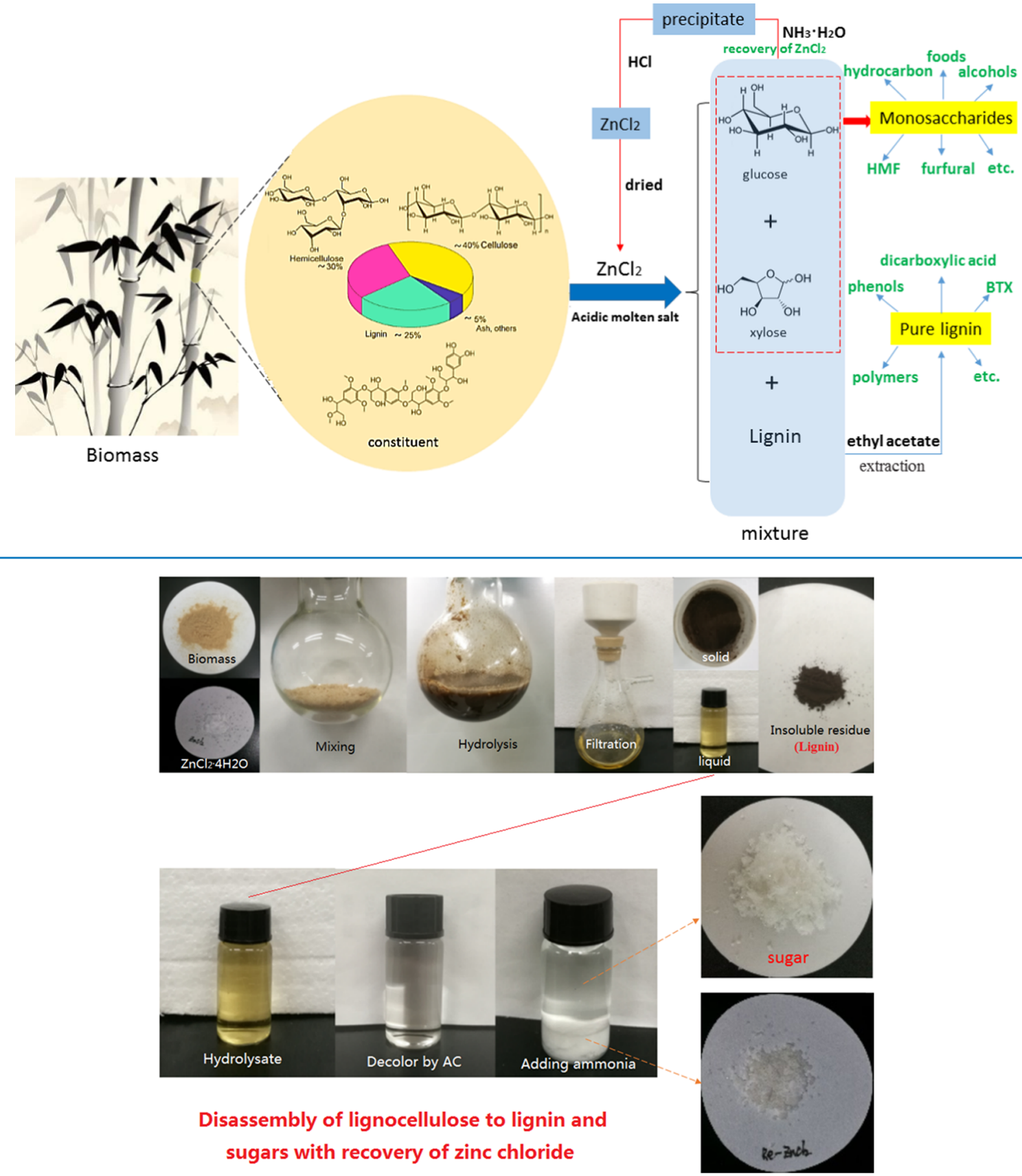

Figure 1. Photographs of lignocellulose (wheat straw) disassembly by acidic zinc chloride hydrate molten salt to lignin and sugars (95 ${ }^{\circ} \mathrm{C}$, 12 min), with recovery of zinc chloride that can be reused by ammonia.

humins from dehydration products of sugars under acidic condition caused lignin overestimation. ${ }^{12}$ The key step of isolation of lignin from lignocellulose is the degradation of polysaccharides, especially cellulose. It is well known that cellulose can be dissolved in some inorganic molten salt hydrates, including $\mathrm{LiClO}_{4} \cdot 3 \mathrm{H}_{2} \mathrm{O}, \mathrm{LiI}_{2} \cdot 2 \mathrm{H}_{2} \mathrm{O}, \mathrm{LiBr} \cdot 3 \mathrm{H}_{2} \mathrm{O}$, $\mathrm{LiSCN} \cdot 2 \mathrm{H}_{2} \mathrm{O}, \mathrm{ZnCl}_{2} \cdot 3 \mathrm{H}_{2} \mathrm{O}, \mathrm{Ca}(\mathrm{NCS})_{2} \cdot 3 \mathrm{H}_{2} \mathrm{O}$, and a eutectic mixture of $\mathrm{NaSCN} / \mathrm{KCN} / \mathrm{LiSCN} \cdot 3 \mathrm{H}_{2} \mathrm{O} .{ }^{4,13}$ Among them, zinc chloride hydrate is most frequently used as a medium to dissolve and hydrolyze cellulose, but it can never be used for lignocellulose directly.

Here, we developed a facile and quick one-step method to isolate high-purity lignin and degrade cellulose and hemi- cellulose to relative monosaccharides from lignocellulosic biomass, and this process is the basis for efficient conversion of lignocellulose to valuable chemicals and materials (Scheme 1). In brief, acidic zinc chloride (AZC) hydrate molten salt was used as a solvent, which could swell and dissolve cellulose and hemicellulose quickly and completely. Meanwhile, cellulose and hemicelluloses can be hydrolyzed under acidic conditions and isolate lignin as an insoluble residue (IR). The structure, composition, and purity of lignin were characterized by means of two-dimensional (2D) heteronuclear single quantum correlation (HSQC) NMR spectroscopy, energy-dispersive spectroscopy (EDS), and Fourier transform infrared (FT-IR) spectroscopy. In addition, an environmentally friendly and 

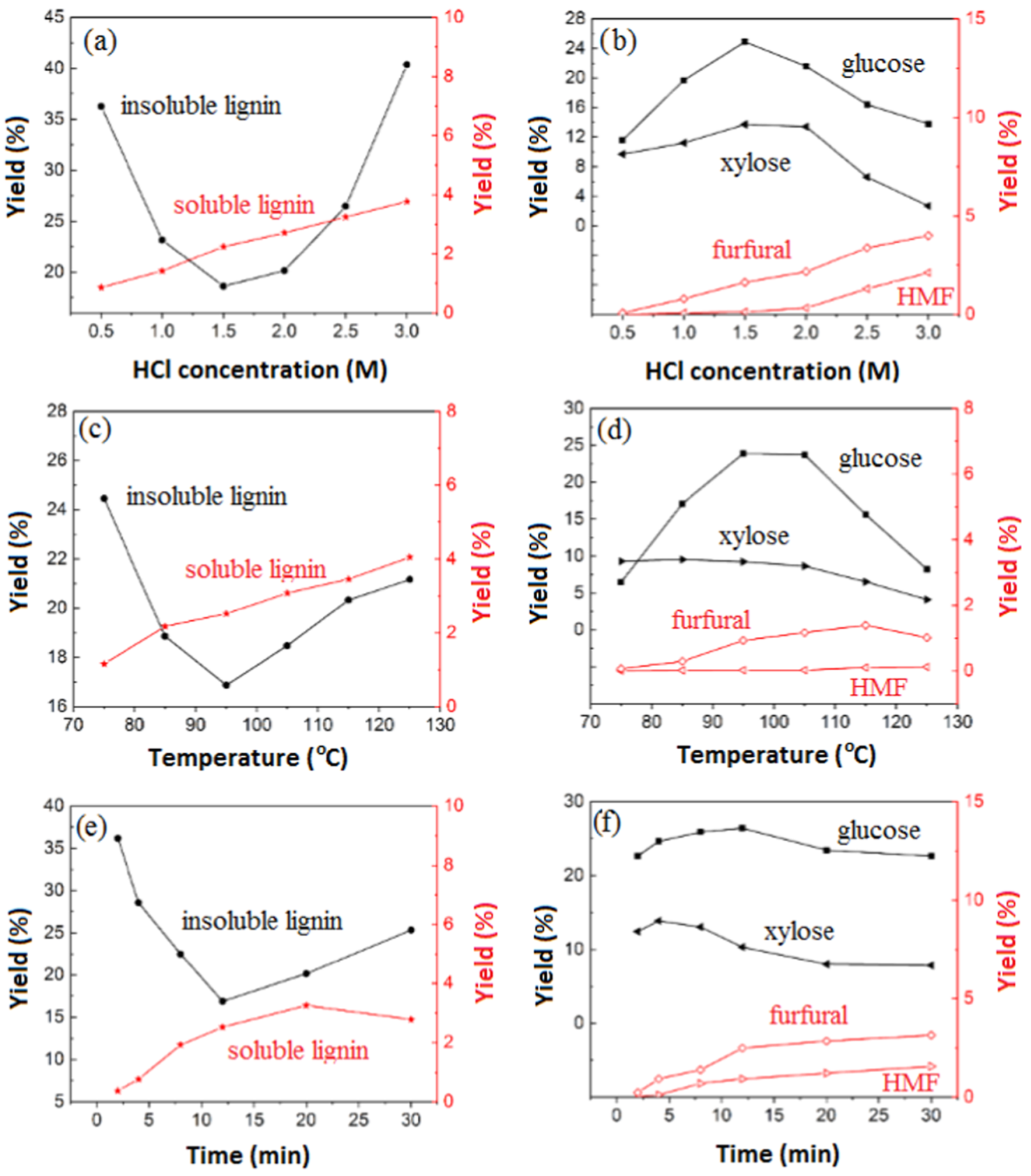

Figure 2. Effects of reaction conditions on yields of insoluble lignin (IL), soluble lignin (SL), glucose, xylose, furfural, and $\mathrm{HMF}$ : $\mathrm{HCl}$ concentration $(a, b)$, reaction temperature $(c, d)$, and reaction time $(e, f)$ (lignocellulose: wheat straw).

efficient method to recycle and reuse zinc chloride from filtrate is developed.

\section{RESULTS AND DISCUSSION}

Isolation and Quantitation of Lignin. Zinc chloride hydrate is a general inorganic salt, whose molten salt is an excellent solvent for cellulose and hemicellulose. This is because the zinc cation $\left(\mathrm{Zn}^{2+}\right)$ and the chloride anion $\left(\mathrm{Cl}^{-}\right)$ are able to interact with the oxygen atoms $(\mathrm{O})$ and hydrogen atoms $(\mathrm{H})$ of the cellulose hydroxyl groups, respectively, and form hydrogen bonds with cellulose. ${ }^{14}$ The cellulose- $\mathrm{Zn}^{2+}$ and cellulose- $\mathrm{Cl}^{-}$interactions will lead to the breakage of the intraand intermolecular hydrogen bonds of cellulose at elevated temperature. In addition, they could destroy the rigorous crystalline structure of cellulose and make it swollen, which can be dissolved. ${ }^{5,13,14}$ Thereby, the glycosidic linkages of the carbohydrates and lignin were exposed fully and cleaved under mild dilute acid conditions. The homogeneous system generated on the basis of dissolution is conducive to facilitate the hydrolysis of hemicelluloses and cellulose. As a result, all kinds of corresponding monosaccharides, such as glucose, xylose, etc., could be obtained. In brief, as shown in Scheme 1, it provides a one-step method to isolate high-purity lignin and monosaccharides (such as glucose, xylose, mannose) from lignocellulosic biomass using acidic zinc chloride. The obtained lignin and monosaccharides can be used as platform feedstock for efficient biorefinery, and valuable chemicals or materials can be obtained from them, which makes the overall utilization of lignocellulose possible. ${ }^{10}$ 

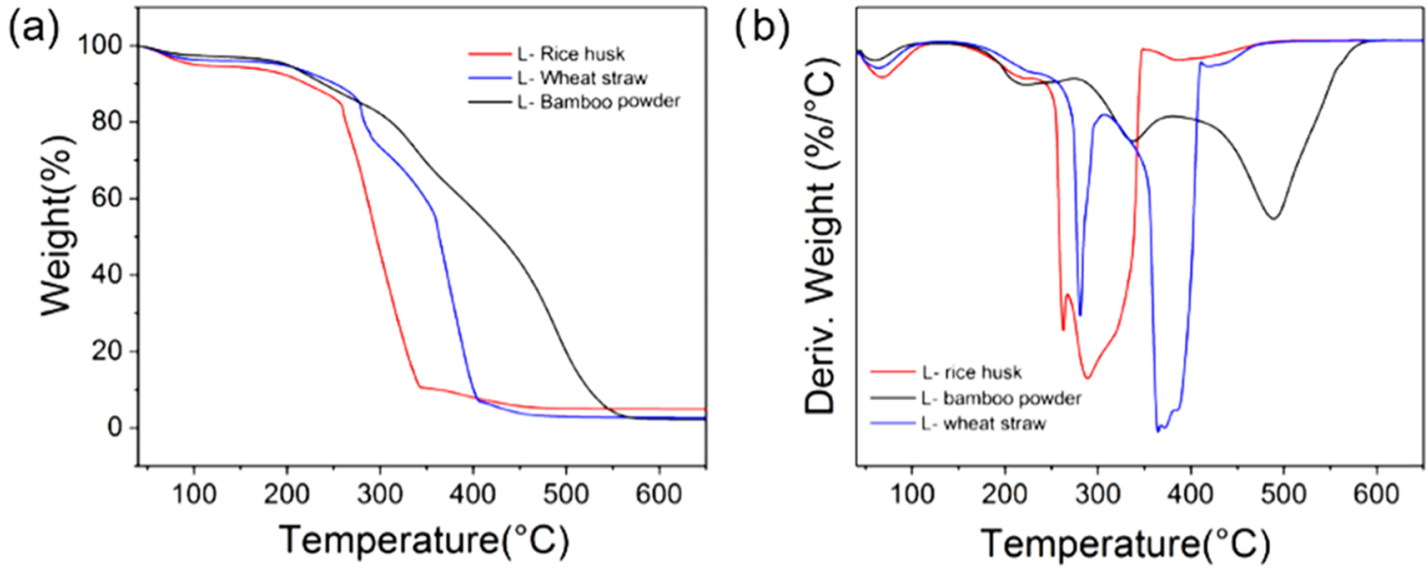

Figure 3. TGA (a) and differential thermogravimetry (b) curves of lignin isolated from various lignocelluloses.

Figure 1 shows the photographs of the processes of fast disassembly of lignocellulose (wheat straw) in acidic molten salt of zinc chloride hydrate and isolation of pure lignin and monosaccharides with the recovery of zinc chloride by ammonia. First, a powder of wheat straw and zinc chloride hydrate was mixed homogeneously and then acidic solution $(\mathrm{HCl})$ was added under stirring at $95{ }^{\circ} \mathrm{C}$. The disassembly of straw was quick and formed a black liquid after $12 \mathrm{~min}$, indicating the complete disassembly of lignocellulose. After adding ethyl acetate, some solid formed and the product was separated into solid and liquid by filtration. The solid is insoluble lignin, whereas the liquid contains soluble zinc chloride and monosaccharides degraded from both cellulose and hemicellulose. After decolorization and addition of ammonium hydroxide, plenty of precipitates of zinc compounds formed. After separating and dissolving the precipitates in hydrochloric acid aqueous solution, a clear transparent solution was obtained, which was heated at $400{ }^{\circ} \mathrm{C}$ to obtain white zinc chloride, indicating the successful recovery of the salt. In addition, when the filtrate was cooled, plenty of white sugars formed, as shown in Figure 1. Clearly, wheat straw was quickly disassembled into lignin and sugars and zinc chloride hydrate can be well recovered.

In addition, under such condition, a small fraction of monosaccharides could be dehydrated to furfural (from pentoses) and 5-hydroxymethylfurfural (HMF, from hexoses). Only a trace amount of the lignin residue could be dissolved and quantitated by UV spectrophotometry.

Factors Affecting Lignin Quantitation Using the AZC Method. Overall, to disassemble lignocellulose, it is vital to remove and hydrolyze cellulose and hemicellulose completely. Although cellulose could be dissolved in zinc chloride molten salt efficiently, its hydrolysis needs Brønsted acid as a catalyst to destroy glycosidic bond. First, acid concentration plays a key role in the efficient and complete hydrolysis of cellulose and hemicellulose. As illustrated in Figure 2a,b, the yield curves of insoluble wheat straw residue dropped to the lowest value of 18.62 wt $\%$ at $1.5 \mathrm{M} \mathrm{HCl}$ aqueous solution. When the acid concentration is less than $1.5 \mathrm{M}$, hemicellulose and cellulose could not be hydrolyzed completely, which can be proved by the low yield of glucose and xylose. However, when the acid concentration reached $2 \mathrm{M}$, even $3 \mathrm{M}$, a high total insoluble residue ( $2 \mathrm{M}$ for $20.15 \mathrm{wt} \%, 3 \mathrm{M}$ for $40.39 \mathrm{wt} \%$ ) was observed, resulting from the carbonization of lignocellulose under high acidic concentration, and it facilitated the dehydration of sugars to HMF and furfural and the formation of humins. Reaction temperature is another crucial factor in the efficient and complete hydrolysis of hemicelluloses and cellulose. Cellulose could hardly be hydrolyzed completely at room temperature even with a high concentration of acid and a long reaction time. A positive reduce toward the insoluble residue was observed when the temperature reached $95{ }^{\circ} \mathrm{C}$. However, when temperature was elevated to $115{ }^{\circ} \mathrm{C}$, the local overheating also caused carbonization of biomass and then dehydration of sugars to HMF and/or furfural was accelerated at the high reaction temperature, which probably leads to the formation of more humus under the acidic condition. As shown in Figure 2c,d, increase of reaction temperature from 75 to 95 ${ }^{\circ} \mathrm{C}$ led to significant reduction of the insoluble residue content from 24.45 to $16.87 \mathrm{wt} \%$ and increase of glucose content from 6.5 to 23.88 wt \%, indicating that high temperature is conducive to remove more carbohydrates. It is worth reminding that further elevating the temperature to 115 or $125{ }^{\circ} \mathrm{C}$ increased the yield of insoluble residue up to 20.34 or $21.17 \mathrm{wt} \%$, which resulted from the carbonization of biomass and the formation of humins. The color of the insoluble precipitate became darker gradually with the extension of reaction time. Meanwhile, the content of xylose and glucose reduced slowly. Therefore, it was important to control the reaction time so that cellulose and hemicellulose were hydrolyzed completely and carbonization or sugar dehydration was avoided. As shown in Figure 1, the content of insoluble residue decreased sharply to $16.87 \mathrm{wt} \%$ in $12 \mathrm{~min}$ and then increased slowly up to $20.15 \mathrm{wt} \%$ at $20 \mathrm{~min}$ and 25.34 wt $\%$ at $30 \mathrm{~min}$, suggesting that the majority of cellulose and hemicellulose were removed from the biomass within $12 \mathrm{~min}$. Then, the content of insoluble residue increased slowly, probably because the carbonization of residual carbohydrates and lignin carbohydrate complex interrelating with lignin was resistant to the dissolution and hydrolysis due to interaction with lignin. In addition, the yield of glucose and xylose obviously increased, but long reaction time will cause monosaccharide dehydration and the accumulation of furans and humins with increasing time.

HMF and Furfural Formation from Sugar Dehydration. During the process, a small portion of HMF and furfural $\left(\lambda_{\mathrm{a}}=240 \mathrm{~nm}\right)$ was generated by the dehydration of sugars, which caused interference with lignin quantitation because of their relatively large extinction coefficients overlap of absorbance. Therefore, it is necessary to correct the acidsoluble lignin absorbance at $240 \mathrm{~nm}$ according to eq 1 

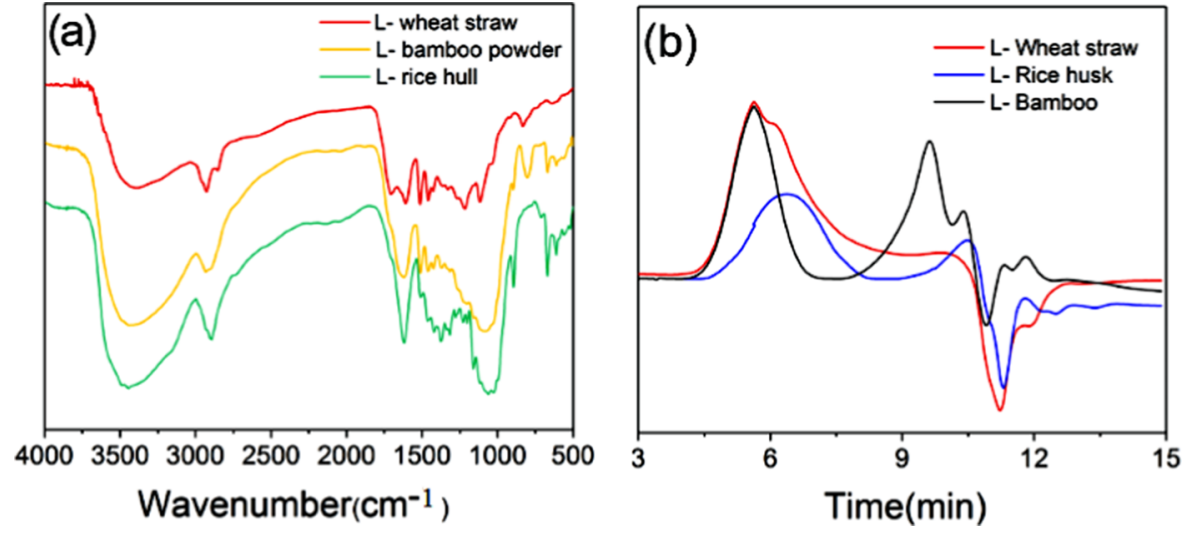

Figure 4. FTIR (a) and GPC (b) spectra of lignin isolated from various lignocelluloses.

$$
\mathrm{Abs}^{\prime}=\mathrm{Abs}_{\mathrm{T}}-\mathrm{Abs}_{\mathrm{f}}
$$

where $\mathrm{Abs}^{\prime}$ is the corrected absorbance of SL at $240 \mathrm{~nm}$, and $\mathrm{Abs}_{\mathrm{T}}$ and $\mathrm{Abs}_{\mathrm{f}}$ are the absorbances of the hydrolysate and furfural/HMF at $240 \mathrm{~nm}$, respectively.

Characterization of the AZC Lignin. To prove that the solid residue from lignocellulose is high-purity lignin by the AZC method, the solid residue was characterized by elemental analysis, thermogravimetric analysis (TGA), FT-IR spectroscopy, X-ray diffraction (XRD), scanning electron microscopy (SEM)-EDS, gel permeation chromatography (GPC), and 2D NMR (HSQC) spectroscopy. First of all, the solid residues were collected and characterized by a Thermo Scientific Flash 2000 series elemental analyzer. Thermal behaviors of solid residues were characterized by thermogravimetric analysis (TGA). As shown in Figure 3, solid residues eventually lose 97.45, 95.24, and $97.39 \%$ of their original weight when the temperature increases up to $550{ }^{\circ} \mathrm{C}$ in air. When the temperature reaches 350,400 , and $550{ }^{\circ} \mathrm{C}$, the lignin residues of rice husk, wheat straw, and bamboo powder lose their mass bluffly until the pyrolysis was almost completed, respectively. The residual solid was ash, whose main components were silicon and inorganic salt. Further, the solid residues adopted two-step sulfuric acid hydrolysis (the NREL method) to detect the trace of residual carbohydrates. As shown in Table S2, only trace amounts of monosaccharides were detected in the filtrate collected from hydrolysis of different species of biomass, suggesting that carbohydrates could be removed from biomass nearly completely through the AZC method.

Then, the three kinds of lignin residue generated from different feedstock were examined by Fourier transform infrared (FT-IR) spectroscopy with a Bruker vector-2 spectrophotometer using the $\mathrm{KBr}$ disk method in the spectral range of $400-4000 \mathrm{~cm}^{-1}$. In the structure of lignin, there are many bonds and functional groups. Although the IR spectrum cannot detect some specific information about each band, it can be used to speculate the structure of lignin and can provide information about its purity. FT-IR spectra of lignin are shown in Figure 4a, and the band assignments are summarized in Table S3. It can be concluded that the as-prepared lignin belongs to the HSG-type lignin from the information of functional group region. The relatively strong and broad peak at $3470 \mathrm{~cm}^{-1}$ contributes to the hydroxyl group, and the band at $1140 \mathrm{~cm}^{-1}$ is characteristic of herbal lignin, which can be explained by the presence of the $S$ units in lignin. Comparing the three kinds of lignin, it can be found that their spectra were almost identical, implying that their structures are close to each other. ${ }^{15}$ The characteristic peaks of 2933 and $2854 \mathrm{~cm}^{-1}$ are attributed to the presence of $\mathrm{C}-\mathrm{H}$ stretching. Considering the structure of lignin, the peaks in the range of $700-850 \mathrm{~cm}^{-1}$ can be assigned to aromatic $\mathrm{C}-\mathrm{H}$. Typically, from 1400 to 1650 $\mathrm{cm}^{-1}$, multiple peaks for $\mathrm{C}=\mathrm{C}$ stretching in aromatics rings skeleton are observed. The presence of a peak at $1713 \mathrm{~cm}^{-1}$ verifies the $\mathrm{C}=\mathrm{O}$ stretching in an $\alpha, \beta$-unsaturated aldehyde or carboxylic acid. In addition, the peak at $1115 \mathrm{~cm}^{-1}$ for $\mathrm{C}-\mathrm{O}$ stretching was assigned to alcohols, esters, and ethers. The molecular weight distributions of lignin were determined by means of GPC ( $N, N$-dimethylformamide, DMF) analysis, and the values of the number-average $\left(M_{n}\right)$ and weight-average $\left(M_{\mathrm{w}}\right)$ molecular weights were calculated from the GPC curves (related to polystyrene standard). As shown in Figure 4b, wheat straw lignin (WSL) and bamboo powder lignin (BPL) exhibited similar molecular weights, 10872 and $9642 \mathrm{~g} \mathrm{~mol}^{-1}$, respectively, and the rice husk lignin (RHL) has a relatively lower molecular weight, which is summarized in Table 1 , as well as the polydispersity index $\left(M_{\mathrm{w}} / M_{\mathrm{n}}\right)$.

Table 1. Molecular Weights $\left(M_{\mathrm{w}}\right.$ and $\left.M_{\mathrm{n}}\right)$ and Polydispersity Index $\left(M_{w} / M_{n}\right)$ of Lignin Isolated from Different Kinds of Lignocellulose

\begin{tabular}{llll} 
& WSL & BPL & RHL \\
$M_{\mathrm{w}}$ & 10872 & 9642 & 6726 \\
$M_{\mathrm{n}}$ & 4854 & 5297 & 3778 \\
$M_{\mathrm{w}} / M_{\mathrm{n}}$ & 2.24 & 1.82 & 1.78 \\
\hline
\end{tabular}

Two-dimensional ${ }^{1} \mathrm{H}-{ }^{13} \mathrm{C}$ NMR (2D NMR) techniques have been used to estimate the purity, structures, and the main linkages of the as-prepared lignin. Although the Klason lignin is indomitable as it is insoluble in any organic solvent, the lignin isolated from lignocellulosic biomass using acidic zinc chloride was found to be soluble in some organic solvents, such as $N, N$ dimethylformamide (DMF), formic acid acid/water (98:2, v/ $\mathrm{v}$ ), and dimethyl sulfoxide (DMSO). ${ }^{16}$ Therefore, about $50 \mathrm{mg}$ of lignin was dissolved directly in $600 \mu \mathrm{L}$ of solvent for the $2 \mathrm{D}$ NMR characterization. The side chains $(\delta \mathrm{C} / \delta \mathrm{H} 50-80 / 2.5-$ $6.0)$ and the aromatic regions $(\delta \mathrm{C} / \delta \mathrm{H} 100-135 / 5.5-8.5)$ of the HSQC spectra of WSL are shown in Figure 5. It is reported that $\beta-\mathrm{O}-4^{\prime}$ (structure $\mathrm{A}$ ) is the predominant type of linkage in native lignin, with small quantified contents of $\beta-5^{\prime}$ (structure B) and $\beta-\beta^{\prime}$ (structure $\mathrm{C}$ ) linkages. ${ }^{17}$ According to previous publications, the amounts of $\beta$-O- $4^{\prime}$ are about $25-40$ per 100 units, and $\beta-5^{\prime}$ (structure $\mathrm{B}$ ) and $\beta-\beta^{\prime}$ (structure $\mathrm{C}$ ) account 

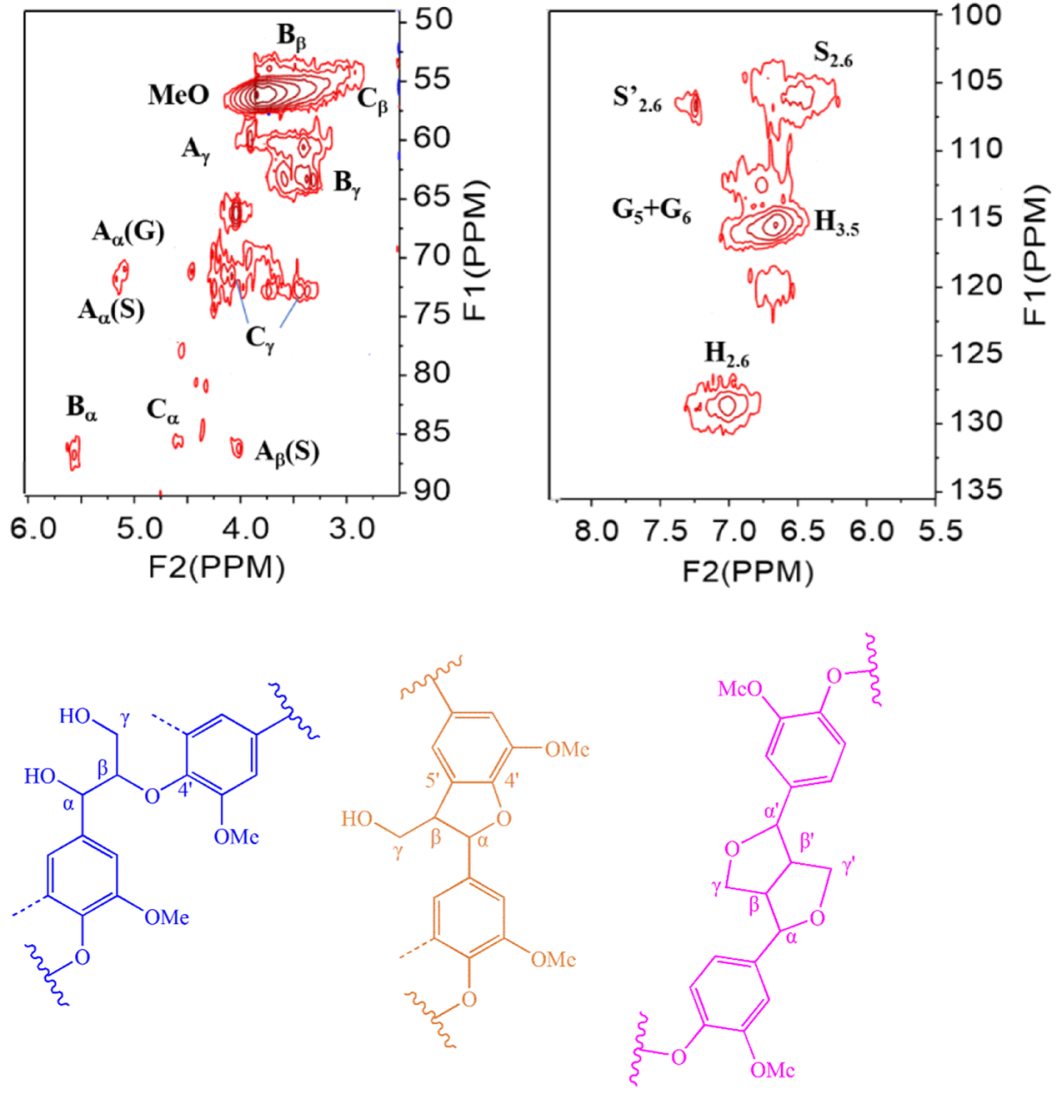

A

B

C

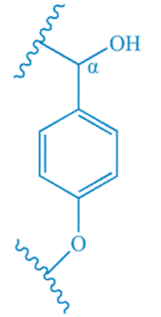

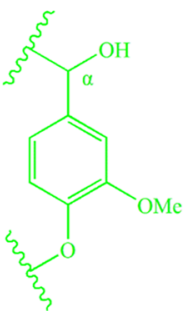

G

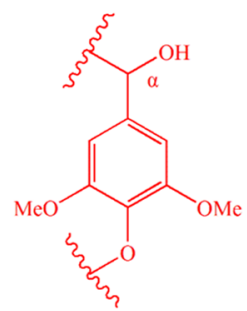

S

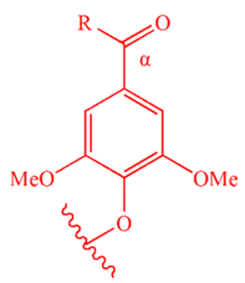

$\mathrm{S}^{\prime}$

Figure 5. $2 \mathrm{D}{ }^{1} \mathrm{H}-{ }^{13} \mathrm{C}$ correlation (HSQC) spectra of WSL.

for $2-5$ and $7-10$ per 100 units in native lignin, respectively. The information of the interunit linkages in lignin can be obtained from the side-chain region $(\delta \mathrm{C} / \delta \mathrm{H} 50-90 / 2.5-6.0)$ of WSL in the 2D-HSQC NMR spectra. As shown in Figure 5 (left), the most prominent signals correspond to methoxy group at $\delta \mathrm{C} / \delta \mathrm{H} 56.13 / 3.74 \mathrm{ppm}$ and several kinds of $\beta$-O- $4^{\prime}$ aryl ether linkages. Among these, the $\mathrm{C}_{\alpha}-\mathrm{H}_{\alpha}$ correlations in structures A linking to $\mathrm{G}$ and $\mathrm{S}$ units were observed at $\delta \mathrm{C} / \delta \mathrm{H}$ $71.66 / 4.86$ and $71.82 / 5.13 \mathrm{ppm}$, respectively. Besides, a small signal and a relatively large signal were identified at $\delta \mathrm{C} / \delta \mathrm{H}$ $85.10 / 4.67$ and $86.76 / 5.62 \mathrm{ppm}$, respectively, and the $\mathrm{C}_{\beta}-\mathrm{H}_{\beta}$ correlations corresponding to the S-type $\beta$-O- $4^{\prime}\left(\mathrm{A}_{\beta}(\mathrm{S})\right)$ and G-type $\beta$-O-4' $\left(\mathrm{A}_{\beta}(\mathrm{G})\right)$ substructures at $\delta \mathrm{C} / \delta \mathrm{H} 85.9 / 4.12$ and $86.8 / 3.99 \mathrm{ppm}$. The $\mathrm{C}_{\beta}-\mathrm{H}_{\beta}$ correlations of structures $\mathrm{B}$ and $\mathrm{C}$ were overlapping with the signal of methoxy group, and they can be discovered at $\delta \mathrm{C} / \delta \mathrm{H} 53.15 / 3.80$ and 53.18/3.27 ppm, respectively. The $\mathrm{C}_{\gamma}-\mathrm{H}_{\gamma}$ correlations in structures $\mathrm{A}, \mathrm{B}$, and $\mathrm{C}$ can be distinguished at $\delta \mathrm{C} / \delta \mathrm{H} 60.65 / 3.40,63.12 / 3.43$, and $71.66 / 4.08$, respectively. Another signal region is the aromatic region in Figure 5 (right), which corresponds to the aromatic rings of guaiacyl $(\mathrm{G}), p$-hydroxyphenyl $(\mathrm{H})$, and syringyl (S) units of lignin. The $\mathrm{C}_{2,6}-\mathrm{H}_{2,6}$ correlations of $\mathrm{S}$ units were prominently observed at $\delta \mathrm{C} / \delta \mathrm{H} 103.8 / 6.71 \mathrm{ppm}$, and the $\mathrm{C}_{\alpha^{-}}$ oxidized $S$ units (structure $S^{\prime}$ ) showed a relatively weak signal at $\delta \mathrm{C} / \delta \mathrm{H} 106.68 / 7.24 \mathrm{ppm}$. Different correlations for the $\mathrm{C}_{5}-$ $\mathrm{H}_{5}$ and $\mathrm{C}_{6}-\mathrm{H}_{6}$ of $\mathrm{G}$ units were observed at $\delta \mathrm{C} / \delta \mathrm{H} 113.46 / 6.76$ and $115.37 / 6.66 \mathrm{ppm}$, respectively, whereas the correlations for the $\mathrm{C} 2-\mathrm{H} 2$ and $\mathrm{C} 6-\mathrm{H} 6$ in $\alpha$-ketone structures oxidized of $\mathrm{G}$ units were observed at $\delta \mathrm{C} / \delta \mathrm{H} 111.24 / 9.39$ and 119.66/6.66 ppm, respectively. In addition, the signals for the $\mathrm{C}_{2,6}-\mathrm{H}_{2,6}$ and $\mathrm{C}_{3,5}-\mathrm{H}_{3,5}$ correlations of substructures $\mathrm{H}$ were clearly observed at $\delta \mathrm{C} / \delta \mathrm{H} 115.37 / 6.66$ and $128.65 / 7.07 \mathrm{ppm}$, respectively, in the aromatic region of the HSQC spectrum of WSL. It should be pointed out that the position of $\mathrm{C}_{3,5}-\mathrm{H}_{3,5}$ correlations in $\mathrm{H}$ units overlapped with guaiacyl 5-positions. ${ }^{18}$ A little fly in the ointment is an unexpected polysaccharide peak that was detected for the $\beta-5$ linkage at $\delta \mathrm{C} / \delta \mathrm{H} \quad 66.36 / 4.04 \mathrm{ppm}$. However, the above observations suggest that the purity of 

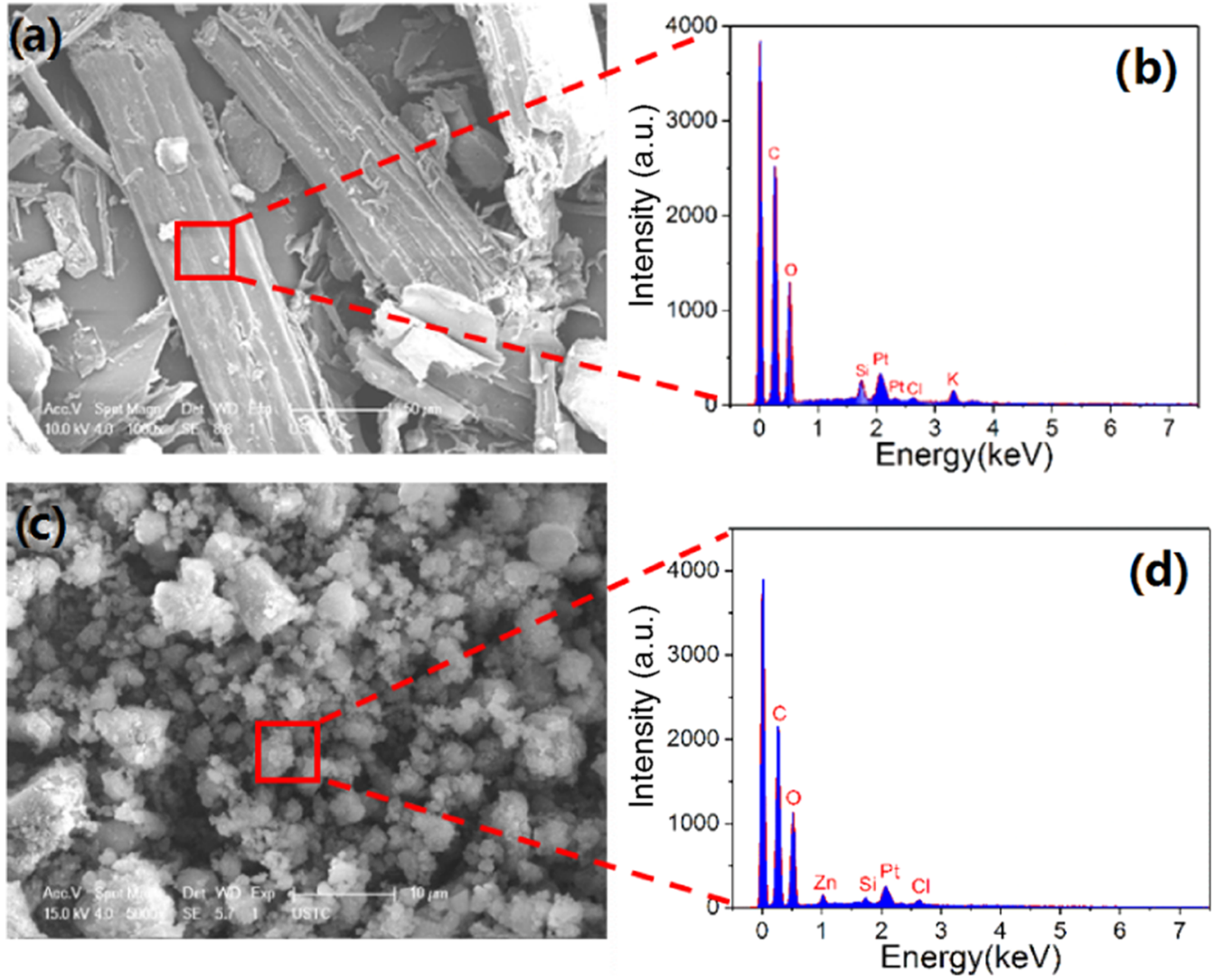

Figure 6. SEM images and EDX spectra of wheat straw (a, b) and insoluble lignin (c, d) after acidic molten salt treatment.

Table 2. Yields of Monosaccharide from Various Lignocelluloses via Acidic Zinc Chloride Molten Salt Treatment

\begin{tabular}{|c|c|c|c|c|c|c|}
\hline biomass & solvent & rhamnose (\%) & xylose $(\%)$ & mannose (\%) & fructose (\%) & glucose (\%) \\
\hline \multirow[t]{4}{*}{ wheat straw } & $\mathrm{f}-\mathrm{ZnCl}_{2}$ & 2.98 & 16.82 & 1.52 & 0 & 26.97 \\
\hline & $\mathrm{r}-\mathrm{ZnCl}_{2}-1$ & 0 & 13.48 & 1.68 & 0 & 24.46 \\
\hline & $\mathrm{r}-\mathrm{ZnCl}_{2}-2$ & 1.04 & 14.19 & 1.77 & 0 & 24.80 \\
\hline & $\mathrm{r}-\mathrm{ZnCl}_{2}-3$ & 0 & 14.03 & 1.47 & 0 & 25.88 \\
\hline \multirow[t]{4}{*}{ bamboo powder } & $\mathrm{f}-\mathrm{ZnCl}_{2}$ & 0 & 9.86 & 0 & 0.21 & 40.56 \\
\hline & $\mathrm{r}-\mathrm{ZnCl}_{2}-1$ & 0 & 8.87 & 0 & 0.13 & 38.87 \\
\hline & $\mathrm{r}-\mathrm{ZnCl}_{2}-2$ & 0 & 10.64 & 0 & 0.17 & 40.32 \\
\hline & $\mathrm{r}-\mathrm{ZnCl}_{2}-3$ & 0 & 9.13 & 0 & 0.09 & 39.64 \\
\hline \multirow[t]{4}{*}{ rice husk } & $\mathrm{f}-\mathrm{ZnCl}_{2}$ & 0 & 5.31 & 0 & 0.18 & 28.15 \\
\hline & $\mathrm{r}-\mathrm{ZnCl}_{2}-1$ & 0 & 4.89 & 0 & 0.07 & 26.43 \\
\hline & $\mathrm{r}-\mathrm{ZnCl}_{2}-2$ & 0 & 5.97 & 0 & 0.11 & 27.68 \\
\hline & $\mathrm{r}-\mathrm{ZnCl}_{2}-3$ & 0 & 6.21 & 0 & 0.13 & 26.75 \\
\hline
\end{tabular}

lignin was very high and the traces of carbohydrates were negligible, which scarcely had any effect on lignin quantitation. ${ }^{15,19}$

In addition, wheat straw and its lignin residue were examined by means of SEM-EDS. As shown in Figure 6, the SEM image indicates that the fiber and sheet structures of the original biomass disappeared and the particle size of the lignin residue was less than $10 \mu \mathrm{m}$, suggesting that carbohydrates have been removed completely from the original lignocellulose. In addition, only a small zinc peak was observed in the energydispersive spectra, indicating that there is less zinc residue. Furthermore, the $\mathrm{C} / \mathrm{O}$ molar ratio of the lignin residue was 1.83, which was similar to the consequence of elemental analysis. These evidences indicate that lignin with excellent purity was separated and prepared successfully.
During the disassembly of lignocellulose, cellulose and hemicellulose can also be efficiently degraded into relative monosaccharides, such as glucose, xylose, etc., and their yield strongly depends on the kind of lignocellulose. As shown in Table 2 , the maximum yield of glucose can reach up to $40 \%$ for bamboo, indicating that it is an efficient method to prepare glucose and xylose, which are the source of various kinds of chemicals and can also be used as nutrition if necessary. For example, they can be used for producing HMF, furfural, hydrocarbon, and alcohols, and lignin can also be used for producing phenols, BTX, dicarboxylic acids, and polymers. During the disassembly processes, high-purity lignin can be obtained with high yields (Table S4), which can be used as feedstock of lignin for further refinery in the near future.

Recovery and Reuse of Zinc Chloride. There are two methods for $\mathrm{ZnCl}_{2}$ recovery. First, $\mathrm{ZnCl}_{2}$ can be extracted from 

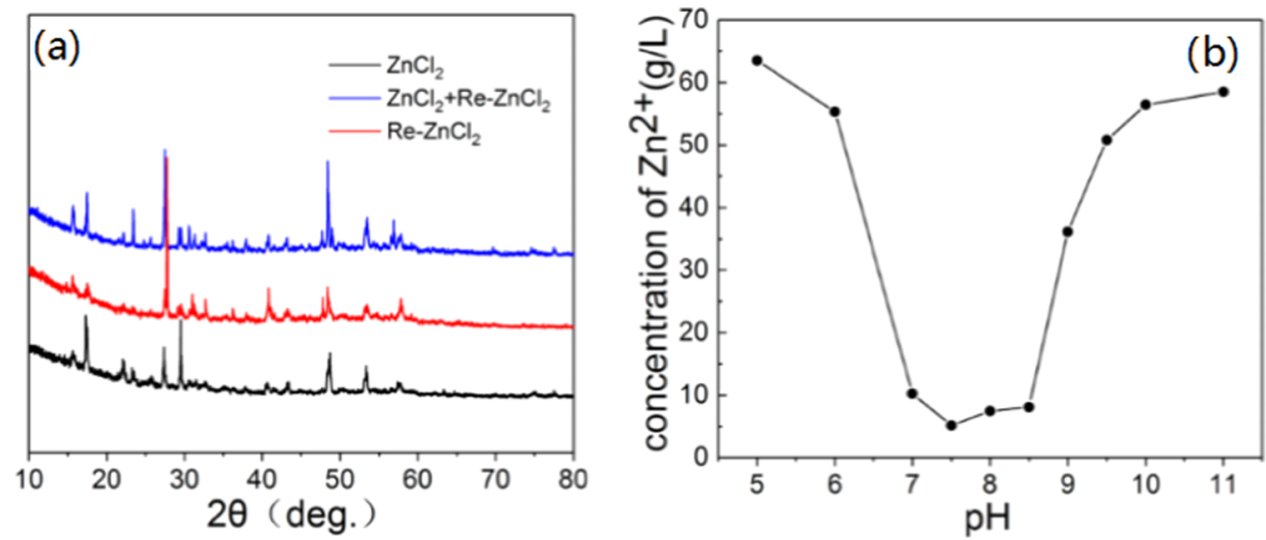

Figure 7. $\mathrm{XRD}$ spectra of fresh and recycled $\mathrm{ZnCl}_{2}$ (a) and effect of $\mathrm{pH}$ on solubility of $\mathrm{Zn}\left(\mathrm{NH}_{3}\right)_{2} \mathrm{Cl}_{2}(\mathrm{~b})$.

an aqueous solution with an organic phase and is subsequently stripped into a solution from which ammine chloride can be crystallized. For example, ethylene glycol is employed as an organic phase and then the mixed solution is contacted with gaseous ammonia to crystallize zinc ammine chloride, followed by heating to recover precipitate and remove ammonia. The second method is a simple hydrometallurgical process for producing anhydrous zinc chloride. The zinc ammine chloride precipitation could be easily achieved by the aqueous solution of ammonium hydroxide, which can be obtained from the hydrolysate by filtering or centrifuging to separate carbohydrates and zinc chloride. The structures and purity of the recycled zinc chloride were characterized by acetic acid salt spray test, XRD, and significant phenomenon of deliquescence in the air. As shown in Figure 7a, the fresh and recycled zinc chloride has the same peaks at $2 \theta$ values, indicating a successful recovery of zinc chloride with a high recovery rate $(\sim 86 \mathrm{wt} \%)$. Meanwhile, the effect of $\mathrm{pH}$ on the solubility of $\mathrm{Zn}\left(\mathrm{NH}_{3}\right)_{2} \mathrm{Cl}_{2}$ has been studied, and as shown in Figure $5 \mathrm{~b}$, when the $\mathrm{pH}$ value was increased from 5 to 7 , the concentration of $\mathrm{Zn}^{2+}$ significantly reduced from 63 to $10 \mathrm{~g} \mathrm{~L}^{-1}$ and reached its lowest point $\left(5 \mathrm{~g} \mathrm{~L}^{-1}\right)$ at $\mathrm{pH}=7.5$. But it began to increase at $\mathrm{pH}=8$, indicating that excess ammonium hydroxide will lead to the dissolution of zinc ammine chloride precipitates. Therefore, the optimum condition to precipitate zinc ions as complete as possible is adding ammonium hydroxide until $\mathrm{pH}=7.5$. Zinc chloride could be recycled successfully based on these studies so that the zinc ion pollution is avoided and a green chemical circle is achieved. Interestingly, the recycled zinc chloride can be reused for disassembly of fresh lignocellulose.

\section{CONCLUSIONS}

Here, we have developed a facile one-step method to isolate lignin from lignocellulosic biomass. Acidic zinc chloride molten salt was used as a reaction medium, which could dissolve and hydrolyze hemicellulose and cellulose quickly and completely, but not lignin. The optimal reaction conditions for this method were zinc chloride molten salt with $1.5 \mathrm{M} \mathrm{HCl}$ at $110{ }^{\circ} \mathrm{C}$ for 12 min, which ensured the complete dissolution and hydrolysis of hemicellulose and cellulose, prevented the carbonization of biomass, and reduced the formation of humus to avoid the overestimation of lignin. The procedure can be finished within 12 min, which is much shorter than the NREL method (3-6 h). In addition, this method was conducted under mild conditions. The reaction medium (acidic zinc chloride) can be easily recycled with no hazardous heavy-metal pollution of zinc ions. Furthermore, the method could be applied to different species of lignocellulose, including wheat straw, bamboo powder, and rice husk, and high-purity lignin can be obtained with high yield of glucose and xylose, which provides a key step to disassemble lignocellulose for green overall utilization in the near future.

\section{EXPERIMENTAL SECTION}

Materials. Lignocellulosic biomass, including rice hull, bamboo powder, and wheat straw, were obtained from Shandong, Anhui, and Shanxi provinces, respectively, and their elemental contents are listed in Table S1. Deionized water with resistivity of $18 \mathrm{M} \Omega \cdot \mathrm{cm}$ was produced from Milli-Q water (Millipore). Zinc chloride $\left(\mathrm{ZnCl}_{2} \cdot 4 \mathrm{H}_{2} \mathrm{O}, 98 \%\right)$ was purchased from Sinopharm Chemical Reagent Co. Ltd. In addition, analytical-grade $\mathrm{H}_{2} \mathrm{SO}_{4}$ (98\%) and hydrochloric acid (37\%) aqueous solutions were purchased from Shanghai Chemical Reagents Company and used directly without further purification. Other reagents, such as chromatographic acetonitrile (99.99\%), furfural (99\%), and 5-hydroxymethylfurfural (HMF, 98\%), were purchased from Aladdin Chemical Reagent Co. Ltd.

Biomass Sample Preparation. Lignocellulosic biomass, such as rice hull, bamboo powder, and wheat straw, were washed, dried, and smashed, and biomass powders between 40 and 80 mesh were collected.

Lignin Isolation by the AZC Method. Lignocellulosic biomass powder ( $1.5 \mathrm{~g}$, weighed to the nearest $0.1 \mathrm{mg}$ ) was mixed with solid zinc chloride and stirred completely in a 50 $\mathrm{mL}$ flask. Then, it was heated in an oil bath at $95^{\circ} \mathrm{C}$ for $10-20$ min under magnetic stirring (400 rpm). Simultaneously, $5 \mathrm{~mL}$ of hydrochloric acid $\left(1.5 \mathrm{~mol} \mathrm{~L}^{-1}\right)$ should be dropped slowly over scheduled time. At the end of dropping, the flask was kept sealed until the solid mixture was immersed into the liquid completely. The mixture was agitated using a magnetic stirring bar $(400 \mathrm{rpm})$ at the preset reaction time. The reaction was quenched by cooling the reactor by ice-water mixture. The native lignin was extracted from the homogeneous solution through liquid-liquid extraction using ethyl acetate. The inorganic solution was collected for the subsequent analysis of sugars and their decomposition products by means of highperformance liquid chromatography (HPLC) within $6 \mathrm{~h}$. All of the organic mixture was filtered under reduced pressure. The solid residues were dried at $85{ }^{\circ} \mathrm{C}$ overnight and then gravimetrically quantitated. Hemicellulose and cellulose were dissolved and hydrolyzed from solid residues, leaving lignin as 
an insoluble residue to be quantitated gravimetrically. The insoluble residue (IR) was calculated using eq 1 , and the insoluble lignin (IL) was calculated using eq 2, which is quantitated by removing the ash. Soluble lignin (SL) was quantitated using eq 3 , according to the Beer-Lambert law on a UV-visible spectrophotometer.

$$
\begin{aligned}
& \operatorname{IR}(\%)=\left[\left(m_{\mathrm{c}+\mathrm{r}}-m_{\mathrm{c}}\right) / m_{\mathrm{s}}\right] \times 100 \\
& \operatorname{IL~}(\%)=\left[\left(m_{\mathrm{c}+\mathrm{r}}-m_{\mathrm{c}}-m_{\mathrm{a}}\right) / m_{\mathrm{s}}\right] \times 100 \\
& \mathrm{SL}(\%)=\left[\left(\operatorname{Abs} \times V_{\mathrm{f}} \times \delta\right) /\left(\varepsilon \times m_{\mathrm{s}} \times l\right)\right] \times 100
\end{aligned}
$$

where $m_{\mathrm{s}}, m_{\mathrm{c}+\mathrm{r}}, m_{\mathcal{O}}$ and $m_{\mathrm{a}}$ are the oven dry weight of sample, weight of the crucible with the insoluble solid residue, the crucible weight, and ash weight, respectively; Abs is the average UV-vis absorbance for the sample at the appropriate wavelength; $V_{\mathrm{f}}$ is the volume of filtrate; $\delta=$ (volume of sample + volume of diluting solvent)/volume of sample; $\varepsilon=$ absorptivity of biomass at specific wavelength $\left(25 \mathrm{~g}^{-1} \mathrm{~L} \mathrm{~cm}^{-1}\right.$ for woody biomass at $240 \mathrm{~nm}$ and $30 \mathrm{~g}^{-1} \mathrm{~L} \mathrm{~cm}^{-1}$ for herbaceous biomass at $320 \mathrm{~nm}$, adopted from the NREL method); and $l=$ path length of the UV-vis cell in centimeters $(1.0 \mathrm{~cm})$.

Preparation of Monosaccharide and Recycling of Zinc Chloride. The filtrate obtained from the procedure of lignin isolation was collected, and some activated carbon was added to decolorize it. Then, the transparent filtrate was collected and ammonium hydroxide aqueous solution was added to form precipitate of zinc chloride ammine by controlling $\mathrm{pH}$ from 7 to 8. The clear transparent filtrate can be obtained through separating the filtrate and precipitate. The mixture of monosaccharides can be crystallized from the filtrate by standing it for a period of time. On the other hand, the white precipitate is extremely stable in air atmosphere and can be easily dissolved by adding hydrochloric acid aqueous solution. Anhydrous zinc chloride could be generated by heating in a tube furnace at $400{ }^{\circ} \mathrm{C}$ for 90 min under nitrogen atmosphere.

Klason Lignin Quantitation by the NREL Method. Quantitation of lignin by the two-stage sulfuric acid hydrolysis was conducted following the NREL standard protocol. In brief, $0.3 \mathrm{~g}$ of biomass (weighed to the nearest $0.1 \mathrm{mg}$ ) was treated in $72 \% \mathrm{H}_{2} \mathrm{SO}_{4}$ at $30{ }^{\circ} \mathrm{C}$ for $60 \mathrm{~min}$. The slurry was diluted to $4 \%$ $\mathrm{H}_{2} \mathrm{SO}_{4}$ and autoclaved at $121{ }^{\circ} \mathrm{C}$ for $60 \mathrm{~min}$. After filtration, the acid-insoluble lignin and the acid-soluble lignin were quantitated gravimetrically and spectrophotometrically, respectively.

Chromatographic Analysis. Monosaccharides in the filtrates were quantitatively analyzed by means of highperformance ion chromatography (HPLC) on a SHIMADZU-GL system equipped with a refractive index detector and a general $1 \mathrm{M} \mathrm{NH}_{2}$ column $\left(4.6 \times 250 \mathrm{~mm}^{2}\right)$ at $40{ }^{\circ} \mathrm{C}$. The mixed solution of acetonitrile and deionized water $(72: 28, \mathrm{v} / \mathrm{v})$ was used as the mobile phase at a flow rate of $1.0 \mathrm{~mL} \mathrm{~min}{ }^{-1}$. The yields of monosaccharides were calculated from the carbon mole ratio after normalizing the monitored concentration of products. The dehydration products (HMF and furfural) of the monosaccharides were determined using HPLC with a Wonda Cr act ODS- 2 column $\left(4.6 \times 250 \mathrm{~mm}^{2}\right)$ at $60{ }^{\circ} \mathrm{C}$ and an UVvis detector at $210 \mathrm{~nm}$. The solution of $0.1 \%$ phosphoric acid

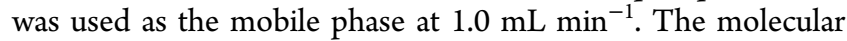
weights of the three lignin preparations were determined by gel permeation chromatography (GPC) on a SHIMADZU-GL system equipped with a refractive index detector and a Shodex GPC KD-804 column at $60{ }^{\circ} \mathrm{C}$. The lignin was dissolved in $N, N$-dimethylformamide (DMF) $\left(\sim 10 \mathrm{mg} \mathrm{mL}^{-1}\right)$ and filtered through a $0.45 \mu \mathrm{m}$ nylon membrane. DMF was used as the

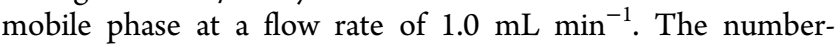
average molecular weight $\left(M_{n}\right)$, weight-average molecular weight $\left(M_{\mathrm{w}}\right)$, and polydispersity index $\left(M_{\mathrm{w}} / M_{\mathrm{n}}\right)$ were calculated using monodispersed polystyrene standards.

NMR Analysis. The NMR spectra were recorded on a Bruker AVIII $400 \mathrm{MHz}$ spectrometer equipped with a $\mathrm{DCH}$ cryoprobe using dimethyl sulfoxide- $d_{6}\left(\mathrm{DMSO}-d_{6}\right)$ as the solvent. For the ${ }^{1} \mathrm{H}-{ }^{13} \mathrm{C}$ heteronuclear single quantum correlation (HSQC) NMR spectroscopy, around $50 \mathrm{mg}$ of lignin was dissolved in $0.5 \mathrm{~mL}$ of DMSO- $d_{6}$. The spectral widths were $12 \mathrm{ppm}$ (from 11 to $-1 \mathrm{ppm}$ ) and $220 \mathrm{ppm}$ (from 200 to $-20 \mathrm{ppm}$ ) for the ${ }^{1} \mathrm{H}$ and ${ }^{13} \mathrm{C}$ dimensions, respectively. The peak of solvent (DMSO- $d_{6}$ ) was used as a reference point of internal chemical shift. Data of spectra were processed using the standard Bruker Topspin-NMR software.

SEM-EDS Analysis. The morphology and elemental distribution of the lignin residue were observed and detected by a field emission scanning electron microscope (Leo Co., Oberkochen, Germany) coupled with an energy-dispersive spectrometer. Lignin residue was tightly fixed on the surface of the conductive tape stuck to the aluminum mount and sputtercoated with a thin layer of platinum before microscopic observation. The accelerating voltage was $10.0 \mathrm{kV}$ for morphology observation and $15.0 \mathrm{kV}$ for EDS analysis.

Other Analysis. The elementary compositions of the lignin residue were recorded by CHONS elemental analysis using the Elementar vario EL cube at $1150{ }^{\circ} \mathrm{C}$. The chemical structure of lignin was examined by means of Fourier transform infrared (FT-IR) spectroscopy with a Bruker vector-2 spectrophotometer (Germany) using potassium bromide $(\mathrm{KBr})$ assay method in the spectral range of $400-4000 \mathrm{~cm}^{-1}$. The thermal stability of the lignin residue was recorded by thermogravimetric analysis (TGA).

\section{ASSOCIATED CONTENT}

\section{Supporting Information}

The Supporting Information is available free of charge on the ACS Publications website at DOI: 10.1021/acsomega.8b00057.

Elemental analysis of feedstock of lignocellulose; residual carbohydrates in insoluble lignin of biomass; band assignment in FT-IR spectra of lignin isolated from wheat straw; and comparison of the obtained lignin with different kinds of lignocellulose (PDF)

\section{AUTHOR INFORMATION}

\section{Corresponding Author}

*E-mail: lfyan@ustc.edu.cn. Tel: +86-551-63606853. Fax: +86551-63603748.

ORCID $\odot$

Lifeng Yan: 0000-0002-6063-270X

Notes

The authors declare no competing financial interest.

\section{ACKNOWLEDGMENTS}

This work was supported by the National Natural Science Foundation of China (Nos. 51673180 and 51373162). 


\section{REFERENCES}

(1) Deuss, P. J.; Lancefield, C. S.; Narani, A.; de Vries, J. G.; Westwood, N. J.; Barta, K. Phenolic acetals from lignins of varying compositions via iron(III) triflate catalysed depolymerization. Green Chem. 2017, 19, 2774-2782.

(2) (a) Choi, Y. S.; Singh, R.; Zhang, J.; Balasubramanian, G.; Sturgeon, M. R.; Katahira, R; Chupka, G.; Beckham, G. T.; Shanks, B. $\mathrm{H}$. Pyrolysis reaction networks for lignin model compounds: unraveling thermal deconstruction of beta-O-4 and alpha-O-4 compounds. Green Chem. 2016, 18, 1762-1773. (b) Lotfi, S.; Boffito, D. C.; Patience, G. S. Gas-Phase Partial Oxidation of Lignin to Carboxylic Acids over Vanadium Pyrophosphate and AluminumVanadium-Molybdenum. ChemSusChem 2015, 8, 3424-3432.

(3) Galkin, M. V.; Samec, J. S. Lignin Valorization through Catalytic Lignocellulose Fractionation: A Fundamental Platform for the Future Biorefinery. ChemSusChem 2016, 9, 1544-1558.

(4) Sen, S.; Losey, B. P.; Gordon, E. E.; Argyropoulos, D. S.; Martin, J. D. Ionic Liquid Character of Zinc Chloride Hydrates Define Solvent Characteristics that Afford the Solubility of Cellulose. J. Phys. Chem. B 2016, 120, 1134-1141.

(5) Sen, S.; Martin, J. D.; Argyropoulos, D. S. Review of Cellulose Non-Derivatizing Solvent Interactions with Emphasis on Activity in Inorganic Molten Salt Hydrates. ACS Sustainable Chem. Eng. 2013, 1, $858-870$.

(6) Deng, W.; Kennedy, J. R.; Tsilomelekis, G.; Zheng, W.; Nikolakis, V. Cellulose Hydrolysis in Acidified LiBr Molten Salt Hydrate Media. Ind. Eng. Chem. Res. 2015, 54, 5226-5236.

(7) Sadula, S.; Oesterling, O.; Nardone, A.; Dinkelacker, B.; Saha, B. One-pot integrated processing of biopolymers to furfurals in molten salt hydrate: understanding synergy in acidity. Green Chem. 2017, 19, 3888-3898.

(8) Li, N.; Pan, X.; Alexander, J. A facile and fast method for quantitating lignin in lignocellulosic biomass using acidic lithium bromide trihydrate (ALBTH). Green Chem. 2016, 18, 5367-5376.

(9) Zhao, Q.; Dixon, R. A. Transcriptional networks for lignin; biosynthesis: more complex than we thought? Trends Plant Sci. 2011, 16, 227-233.

(10) Gabov, K.; Gosselink, R. J.; Smeds, A. I.; Fardim, P. Characterization of lignin extracted from birch wood by a modified hydrotropic process. J. Agric. Food Chem. 2014, 62, 10759-10767.

(11) (a) Alvira, P.; Tomas-Pejo, E.; Ballesteros, M.; Negro, M. Pretreatment technologies for an efficient bioethanol production process based on enzymatic hydrolysis: A review. Bioresour. Technol. 2010, 101, 4851-4861. (b) Behling, R.; Valange, S.; Chatel, G. Heterogeneous catalytic oxidation for lignin valorization into valuable chemicals: what results? What limitations? What trends? Green Chem. 2016, 18, 1839-1854.

(12) (a) Tsilomelekis, G.; Orella, M. J.; Lin, Z.; Cheng, Z.; Zheng, W.; Nikolakis, V.; Vlachos, D. G. Molecular structure, morphology and growth mechanisms and rates of 5-hydroxymethyl furfural (HMF) derived humins. Green Chem. 2016, 1983-1993. (b) van Putten, R. J.; van der Waal, J. C.; de Jong, E.; Rasrendra, C. B.; Heeres, H. J.; de Vries, J. G. Hydroxymethylfurfural, a versatile platform chemical made from renewable resources. Chem. Rev. 2013, 113, 1499-1597.

(13) Yang, Y. J.; Shin, J. M.; Kang, T. H.; Kimura, S.; Wada, M.; Kim, U. J. Cellulose dissolution in aqueous lithium bromide solutions. Cellulose 2014, 21, 1175-1181.

(14) Cao, N. J.; Xu, Q.; Chen, C. S.; Gong, C. S.; Chen, L. F. Cellulose Hydrolysis Using Zinc-Chloride as a Solvent and Catalyst. Appl. Biochem. Biotechnol. 1994, 45-46, 521-530.

(15) Yuan, T. Q.; Sun, S. N.; Xu, F.; Sun, R. C. Characterization of lignin structures and lignin-carbohydrate complex (LCC) linkages by quantitative $13 \mathrm{C}$ and 2D HSQC NMR spectroscopy. J. Agric. Food Chem. 2011, 59, 10604-10614.

(16) Nishiwaki-Akine, Y.; Watanabe, T. Dissolution of wood in $\alpha$ keto acid and aldehydic carboxylic acids and fractionation at room temperature. Green Chem. 2014, 16, 3569-3579.
(17) Yuan, T. Q.; Sun, S. N.; Xu, F.; Sun, R. C. Structural characterization of lignin from Triploid of Populus tomentosa Carr. J. Agric. Food Chem. 2011, 59, 6605-6615.

(18) (a) Sun, R. C.; Tomkinson, J.; Sun, X. F.; Wang, N. J. Fractional isolation and physico-chemical characterization of alkali-soluble lignins from fast-growing poplar wood. Polymer 2000, 41, 8409-8417. (b) Önnerud, H.; Gellerstedf, G. Inhomogeneities in the chemical structure of hardwood lignins. Holzforschung 2003, 57, 255-265. (c) Marchessault, R. H.; Coulombe, S.; Morikawa, H.; Robert, D. Characterization of poplar exploded wood lignin. Can. J. Chem. 1982, 60, 2372-2382. (d) Nimz, H. H.; Robert, D.; Faix, O.; Nemr, M. Carbon-13 NMR spectra of lignins, 8 structural differences between lignins of hardwoods, softwoods, grasses and compression wood. Holzforschung 1981, 35, 16-26. (e) Lapierre, C.; Lallemand, J. Y.; Monties, B. Evidence of poplar lignin heterogeneity by combination of 13C and 1H NMR spectroscopy. Holzforschung 1982, 36, 275-282.

(19) (a) Foston, M.; Samuel, R.; He, J.; Ragauskas, A. J. A review of whole cell wall NMR by the direct-dissolution of biomass. Green Chem. 2016, 18, 608-621. (b) Gabov, K.; Gosselink, R. J. A.; Smeds, A. I.; Fardim, P. Characterization of Lignin Extracted from Birch Wood by a Modified Hydrotropic Process. J. Agric. Food Chem. 2014, 62, 1075910767. 